\title{
Technoscience, Neuroscience and the Subject of Politics
}

One of the central tenets of today's hegemonic ideology holds that the "end" of metaphysics has opened up the horizon for a post-metaphysical recognition of the narrative character of history, society, knowledge, truth, and the subject. While this narrative model has been dominant for quite some time in historiography, in philosophies of history, in sociological accounts of mass media and even in some psychoanalytic accounts, postmodern-hermeneutic philosophers such as Gianni Vattimo have even claimed that the most recent developments in the positive sciences

- that have taken on the form of technoscience - can no longer simply be characterized in terms of objectification, availability and calculability, but rather in terms of a tendency towards incalculability and non-objectivity. ${ }^{1}$ That is, scientific attempts to objectify "nature" have led to a dissolution of their object into narratives that are to be interpreted. Thus, technoscience no longer speaks of objective facts, but of hypotheses and interpretations. Consequently, it is claimed that some kind of aesthetic-narrative model is operative even in accounts of new paradigms within the domain of technoscience.

It is contemporary technoscience itself that transforms the world into a place where there are no longer facts guided by the "principle of reality", but only multiple narratives that are to be interpreted and judged without having recourse to traditionally modern metaphysical, legitimating meta-narratives. In short, 
technoscience has become an anti-model to stable systems, a model for open systems no longer allowing for some unity of reason, language or subject. ${ }^{2}$

Taking as his point of departure Heidegger's definition of modernity as "the age of the world picture", Vattimo attempts to draw the nihilistic consequences from the modern production of the Weltbild, in that the point where science's movement to the extreme of calculability leads to a general incalculability, that is, to the dissolution of the world picture into conflicting images, marks "a first flashing of the new event of Being"3 to the extent that it brings with it a dissolution of the metaphysical traits of experience. This weakening or erosion of metaphysical reality implies that reality is "the result of the intersection and 'contamination' ... of a multiplicity of images, interpretations and reconstructions ... without 'central' coordination.",

Recasting the objectivity of reality in terms of a complex, dense, and non-transparent technological web of images entails also consequences for the traditional metaphysical conception of the subject. Similar to the weakening of reality and world "into a sort of residue, a crystallization of the "conflict of interpretations", 5 the subject can be less and less conceived of as a "center of self-consciousness and decision-making, reduced as it is to being the author of statistically predicted choices, playing a multiplicity of social roles that are irreducible to a unity." ${ }^{6}$ That is to say, the postmodern-hermeneutic interpretation of the contemporary constellation of science and technology opens up the domain of shifting identities, thereby announcing and performing the end of the Cartesian cogito. The metaphysical distinction between subject and self has become obsolete, in so far as the subject now becomes reducible to and identical with a multiplicity of "selves", of "partial centers". 
Finally, a "collateral benefit" of technoscience's production of a plural society is the "radical transformation ... in the nature of political power.", That is, by dissolving metaphysical accounts of objective reality and of the subject, contemporary technoscience's own de-centering has enabled democracy to come into its own. The essential link between science and technology on the one hand, democracy on the other, can be discerned in their respective emancipatory possibilities, in that they partake "in the dissolution of the strong, centralized, authoritarian structures of political power, thus contributing decisively ... to create the chance for being to give itself (to occur, to presence) outside metaphysics' violent and objectifying patterns."

Hence Vattimo’s declaration: “The end of metaphysics has its genuine political parallel in the strengthening of democracy." It is only this postmodern ontology of the weakening of Being - a weakening brought about precisely and decisively by contemporary constellation of science and technology - that can supply "philosophical reasons for preferring a liberal, tolerant, and democratic society rather than an authoritarian and totalitarian one." 10

As if to provide a further exemplification and illustration of Vattimo's thesis that contemporary science is the principal agent in the pluralizing dissolution of central modern metaphysical concepts, Daniel Dennett's magnificent Consciousness Explained endeavors, precisely by means of a neuroscientific account of the emergence of (self-)consciousness out of physical, biological processes, to "weaken" the Cartesian theater (the cogito) (as well as the Freudian unconscious) into a mere, always temporary and provisional, "center of narrative gravity." 
According to Dennett, the Cartesian theater is a false "metaphorical picture of how conscious experience must sit in the brain"; ${ }^{11}$ that is, against this false assumption governing Cartesian dualism as well as various types of materialism in the wake of Descartes, one has to recognize that, once the res cogitans is discarded, "there is no longer a role for a centralized gateway or indeed for any functional center to the brain. The pineal gland is not only not the fax machine to the Soul, it is also not the Oval Office of the brain, and neither are any other portions of the brain." ${ }^{2}$ Thus, Dennett proposes the "multiple drafts" model in which "all varieties of perception - indeed, all varieties of thought or mental activity - are accomplished in the brain by parallel, multi-track processes of interpretation and elaboration of sensory inputs. $" 13$ Dennett leaves the space of theater (with its observer) and moves to a process of production that is to illuminate further the multiple drafts model: a kind of (re-)writing project or, to be more precise, a kind of perpetual editorialism:

In the world of publishing there is a traditional and usually quite hard-edged distinction between pre-publication editing, and post-publication correction of 'errata'. In the academic world today, however, things have been speeded up by electronic communication. With the advent of word-processing and desktop publishing and electronic mail, it now often happens that several different drafts of an article are simultaneously in circulation, with the author readily making revisions in response to comments received by electronic mail. Fixing the moment of publication, and thus calling one of the drafts of the article the canonical text - the text of record, the one to cite in a bibliography - becomes a somewhat arbitrary manner. ${ }^{14}$ 
This passage seems to entertain a certain affinity between neuroscientific findings and some of Vattimo's claims - not only with regard to the significance of both technoscience and neuroscience concerning (the production) of meaning, but also with regard to the transformations that both object and subject undergo within the frame of technoscience and neuroscience: what occurs in both frameworks on the object-side amounts to a dissolution of substance, of authority and finality; and on the side of the subject, one finds a dissolution to the cogito and its instantaneity in that all temporal stability is relinquished for the sake of an appeal to multiple drafts or narratives in order to account for the generation of the self out of the interactions of the mechanisms of consciousness.

This perpetual editorialism also characterizes the way in which Dennett inscribes language into his project of elaborating a theory naturalizing consciousness. In analogy to discarding the res cogitans, he dismisses, in the field of language, assumptions about a "Central Meaner" or a "Conceptualizer"; instead, he replaces these two particular images of a centralized bureaucracy with a "pandemonium of word demons", of competing forces (words, phrases, syntactic figures) generating a universe of tinkering and opportunistic enlisting. Meaning thus becomes displaced, dislocated from a surreptitiously assumed central location.

Dennett conceptualizes the human mind in terms of a multitude of vaguely coordinated soft wares or programs created by evolution, over-determining the structure of the human mind in such a way that one can neither identify isolated particular organs with clearly defined functions nor a universal self coordinating between them; rather, some particular program or narrative fragment can temporarily 
assume the coordinating function, preventing the "pandemonium of word demons" from regressing into chaos "thanks to good meta-habits that tend to entertain coherent, purposeful sequences rather than an interminable helter-skelter power grab." ${ }^{, 15}$ The plasticity of the brain forms the evolutionary backdrop for Dennett's neuroscientific explanation of meta-habits. Although nervous systems are more or less hard-wired and usually fully adequate to cope with the environment of an organism, the "plastic brain is capable of reorganizing itself adaptively in response to particular novelties in the organism's environment." ${ }^{\prime 16}$ It is this very plasticity of the brain that allows for the installation of new and flexible softwares atop the more rigid platform of the brain's hardware. Dennett's account of the formation of meta-habits passes through auto-stimulation, memes and the "virtual machine", finally arriving at "human consciousness as a huge complex of memes ... that can be best understood as the operation of a ... virtual machine implemented in the parallel architecture of the brain that was not designed for any such activities."17 This installation of a virtual machine creates "thousands or millions of billions of connection-strength settings between neurons, which all together in concert give the underlying hardware a new set of macro-habits, a set of conditional regularities of behavior."18

Finally, the self has to be interpreted rather as "an abstraction defined by the myriads of attributions ... that have composed the biography of the living body whose Center of Narrative Gravity it is." ${ }^{, 19}$ For "an advanced agent must build up practices for keeping track of both its bodily and 'mental' circumstances. In human beings, ... those practices mainly involve bouts of storytelling and story checking, some of it factual and some of it fictional." ${ }^{20}$ Ultimately, the self reveals itself to be a narrative fiction, but an effective fiction. Dennett writes: “'Call me Dan,' you hear from my lips, 
and you oblige, not by calling my lips Dan, or my body Dan, but by calling me Dan, the theorist's fiction created by ... well, not by me but by my brain, acting in concert over the years with my parents and siblings and friends." 21

Dennett's evolutionary narrative (that is also and at the same time a narrative about the evolutionary development of narrative) does not only intend to explain some kind of direct passage from natural to symbolic environs, from nature to culture, but also to foreclose definitively any space for the articulation of the Cartesian cogito (or of the Freudian unconscious). For what they both presuppose is "a unified agent (the subject, the unconscious), which controls and directs the course of events, and Dennett's point is, precisely, that there is no such agent. ${ }^{, 22}$ However, instead of relegating both the Cartesian cogito (and the Freudian unconscious) into the dustbin of (the) history (of philosophy), Slavoj Žižek attempts to show in his largely sympathetic reading of Dennett that, precisely, Dennett's recourse to an evolutionary account of the emergence of narrative bears witness to some "repressed". That is to say, Dennett's narrative conception of (self-)consciousness, according to which conscious experience and self-identity emerge out of "opportunistic tinkering" within a field of the multiplicity of memes vying for hegemony fails to account "for the very form of narrative - where does the subject's capacity to organize its contingent experience into the form of the narrative come from? Everything can be explained this way except the narrative form itself, which, in a way, must already be there." ${ }^{23}$ What remains unaccounted for in Dennett's theoretical mixture of the experimental and the interpretative is the very passage - via negativity - from nature/biology to culture; the recourse to the figure of narrative seems to obscure the space and the cut or gap separating the neuronal from the mental by relaying scientific explanation by 
interpretation; in other words, the failure to account for the very form of narrative preceding its content - which, in Dennett, is simply presupposed -, can be deciphered as "the unfailing index of the violent repression of some traumatic content", ${ }^{24}$ in addition, is Dennett's evolutionary-narrative account regarding the passage from nature to culture without any theoretical fissure not ideological, in so far as "narrative as such emerges in order to resolve some fundamental antagonism by way of rearranging its terms into a temporal succession?"25

Dennett's text turns out to be woven by complex layers of different narratives: ${ }^{26}$ first, the functioning of the brain is accounted for in terms of multiple drafts or narratives; then, an evolutionary narrative is inscribed into this model (about the multi-narrative structure of the brain). Finally, this narrative of natural history seems to project a concurrent narrative of social history that reveals itself in turn as a highly condensed story about the postmodern condition, in that one decisive figurality permeates, organizes and gives consistency to Dennett's textual narrative: the figurality of the political. That is to say, the Cartesian theater is not only a false scientific model, but also, and perhaps more importantly, a false political representational medium: for it is "dictatorial", a simulation of the "Oval Office"; it operates with the assumption of a “Boss", a "Central Meaner" or "Conceptualizer". Ultimately, what hides on the centralized stage of the Cartesian theater is the (bureaucratic, centralized) State. What is the alternative?

It is all very well to equip oneself with an 'All hands on deck!' subroutine, but then, once all hands are on deck, one must have some way of coping with the 
flood of volunteers. We should not expect there to have been a convenient captain already at hand ..., so conflicts between volunteers had to sort themselves out without any higher executive. ${ }^{27}$

However, it is here that "an internal political miracle" can be discerned, in so far as the de-centered brain "creates a virtual captain of the crew, without elevating any of them to long-term dictatorial power. Who's in charge? First one coalition and then another, shifting in ways that are not chaotic thanks to good meta-habits ...".28

Consequently, Dennett's naturalist "explanation" of consciousness carries within itself the - neuroscientifically substantiated - claim to a vision of politics whose contours may be discerned in terms of a conception of a radical, anti-essentialist and decentralized democracy whose political understanding and practice of commanding resembles recent theories of hegemony. Dennett's account shows not only that brain has a history and is a history - that is, a constitutive historicity of the brain -, but also a consciousness of this historicity, encapsulated in his particular radical-democratic political vision. $^{29}$

What thus come to the fore is the question of the relation between the neuronal and the political. In a way, Dennett's vision of the brain is political: neuronal functioning as described by Dennett quite closely resembles a democracy; thus, in one sense, Dennett's explanation of consciousness has certainly "contributed to the political emancipation of the brain"; ${ }^{30}$ on the other hand, would one not also have to interrogate whether his "scientific description of the brain engenders a certain 
normalizing vision of democracy, in that it accords an overly central role to the absence of center, a too rigid prominence to plasticity as flexibility?" ${ }^{31}$ Is his narrative of multiple drafts to be understood as mere polymorphism, open to all forms, all shifting identities, all subjectivations within the neuronal-democratic frame, or does it also open up a space for a negation of and resistance to democracy that could not that easily be dismissed as some kind of "totalitarianism"?

Thus, are not both Vattimo's postmodern-hermeneutic and Dennett's postmodernscientific theories, precisely in pretending to raise the veil (their critique of Cartesianism as philosophical, scientific, and political theory), perhaps reinforcing a different veil (that of democratic fundamentalism) in producing no critical analysis of what might drive both contemporary technoscience and neuroscience? By ascribing to postmodern multi-narrative cerebral and technoscientific structures the weakening force that creates the conditions for the democratic proliferation of multiple fluid narratives and (communal) identities, both may have neglected capital's force of deterritorialization providing the very (disavowed) horizon for the affirmation of playful, fictive narrative differences playing across all boundaries. And if it is correct, that neuronal man is never simply a neuronal given, but also a political and ideological construction, what can be done so that accounts of neuro-science and techno-science do not simply naturalize democracy as the political mode of organization? After all, if liberal pluralist democracy with its ideology of narrative self-fashioning and of flexible, adaptable and ultimately docile identities continues to be the political form of (late) capitalism covering up the antagonism constitutive of the economic-political process, should one not attempt to free neuroscience and technoscience precisely from unwittingly reproducing the current socioeconomic 
organization by subjecting them to an ideology critique that unlocks their potential as explosive sites?

\section{Erik Vogt}

Trinity College,

Department of Philosophy

300 Summit Street, Hartford, CT 06106

\section{USA}

erik.vogt@trincoll.edu

\footnotetext{
${ }^{1}$ See Gianni Vattimo, Beyond Interpretation: The Meaning of Hermeneutics for Philosophy, trans.

David Webb (Stanford: Stanford University Press, 1997).

${ }^{2}$ Ibid., $15-27$.

${ }^{3}$ Gianni Vattimo, The Transparent Society, trans. David Webb (Baltimore: The Johns Hopkins University Press, 1992), 7.

${ }^{4}$ Ibid., 7.

${ }^{5}$ Gianni Vattimo, Nihilism \& Emancipation: Ethics, Politics, \& Law, ed. Santiago Zabala, trans.

William McCuaig (New York: Columbia University Press, 2005), 17.

${ }^{6}$ Vattimo, Transparent Society, 117.

${ }^{7}$ Gianni Vattimo, "Democracy, Reality, and the Media: Educating the Übermensch," in Democracy and the Arts, ed. Arthur M. Melzer, Jerry Weinberger, M. Richard Zinman (Ithaca, N.Y.: Cornell University Press, 1999), 145 - 58; 150.

${ }^{8}$ Ibid., 154.

${ }^{9}$ Vattimo, Nihilism \& Emancipation, 83.

${ }^{10}$ Ibid., 19.

${ }^{11}$ Daniel Dennett, Consciousness Explained (Boston: Back Bay Books, 1992), 107.

${ }^{12}$ Ibid., 106.
} 
${ }^{13}$ Ibid., 111.

${ }^{14}$ Ibid., 125.

${ }^{15}$ Ibid., 171.

${ }^{16}$ Ibid., 188.

${ }^{17}$ Ibid., 210.

${ }^{18}$ Ibid., 218.

${ }^{19}$ Ibid., 247.

${ }^{20}$ Ibid., 428 .

${ }^{21}$ Ibid., 429.

${ }^{22}$ Slavoj Žižek, "The Cartesian Subject versus the Cartesian Theater", in Cogito and the Unconscious, ed. S. Žižek (Durham and London: Duke University Press, 1998), 247 - 274; 254.

${ }^{23}$ Ibid., 255.

${ }^{24}$ Ibid., 256.

${ }^{25}$ Ibid., 256.

${ }^{26}$ As to this account of the perpetual editorialism and layering of narratives in Dennett, I am indebted here to Fredric Jameson's unpublished manuscript entitled „Consciousness Explained Allegorically“.

${ }^{27}$ Dennett, Consciousness Explained, 188.

${ }^{28}$ Ibid., 228.

${ }^{29}$ See Catherine Malabou, What Should We Do with Our Brain? Foreword by Marc Jeannerod; trans. Sebastian Rand (New York: Fordham University Press, 2008), 1 - 2. This is Malabou's central critique, which is here reproduced.

${ }^{30}$ Ibid., 53.

${ }^{31}$ Ibid., 53. 